\title{
Effects of Treated Cow Dung Addition on the Strength of Carbon-Bearing Iron Ore Pellets
}

\author{
Qing-min Meng, ${ }^{1}$ Jia-xin Li, ${ }^{1,2}$ Tie-jun Chun, ${ }^{1}$ Xiao-feng He, ${ }^{1}$ Ru-fei Wei, \\ Ping Wang, ${ }^{1}$ and Hong-ming Long ${ }^{1,3}$ \\ ${ }^{1}$ School of Metallurgical Engineering, Anhui University of Technology, Ma'anshan, Anhui 243002, China \\ ${ }^{2}$ School of Metallurgy, Northeastern University, Shenyang 110819, China \\ ${ }^{3}$ Key Laboratory of Metallurgical Emission Reduction \& Resources Recycling, Anhui University of Technology, \\ Ministry of Education, Maanshan 243002, China
}

Correspondence should be addressed to Hong-ming Long; yaflhm@126.com

Received 25 June 2017; Accepted 25 September 2017; Published 2 November 2017

Academic Editor: Merrick Mahoney

Copyright (C) 2017 Qing-min Meng et al. This is an open access article distributed under the Creative Commons Attribution License, which permits unrestricted use, distribution, and reproduction in any medium, provided the original work is properly cited.

It is of particular interest to use biomass as an alternative source of fuel in direct-reduction ironmaking to ease the current reliance on fossil fuel energy. The influence of cow dung addition on the strength of carbon-bearing iron ore pellets composed of cow dung, iron ore, anthracite, and bentonite was investigated, the quality of green and dry pellet was evaluated based on FTIR analysis, and the mechanism of strength variation of the reduced pellets was investigated by analysing the phase composition and microstructure using XRD and SEM. The results show that cow dung addition decreased the green pellet strength due to expansion of the amorphous region of the cellulose in the cow dung; however, the dry pellet strength increased substantially. In the process of reduction roasting, it was found that cow dung addition can promote aggregation of iron crystals and increase the density of the pellets, resulting in increased strength of the reduction roasted pellets, while excessive cow dung addition resulted in lower strength.

\section{Introduction}

With the gradual depletion of raw materials for the blast furnace, such as coke and quality iron ore, direct-reduction and smelting reduction technologies using gas, liquid fuels, and noncoking coal as energy sources were developed as cleaner, more environment friendly alternatives, which have been applied widely around the world [1-3]. However, the fuel sources of noncoking coal iron-making technology have not fundamentally changed, and there is a gap in product quality and energy consumption compared to the blast furnace. The use of biomass as an alternative fuel source, to further reduce the consumption of fossil fuels and emission of carbon in the steel-making industry, has become a hot topic among scholars [4-8]. Sterol [9] investigated the mechanisms of iron ore reduction with biomass wood waste. The results showed that the iron ore was successfully reduced to predominantly metallic iron when up to $30 \mathrm{wt} \%$ of biomass was introduced into the mixture and reduction commenced at approximately
$943 \mathrm{~K}$ and was almost completed at $1473 \mathrm{~K}$. Wei et al. [10] studied the characteristics and kinetics of iron oxide reduction by carbon in biomass composites. The result showed that iron oxide can be reduced by biomass very rapidly, and the degree of metallisation and reduction increased with temperature.

Iron oxide reduction by carbon in biomass can be divided into two stages, namely, reduction by volatile matter followed by reduction by nonvolatile carbon. The reduction times of the two stages both decrease with increasing temperature. Liu et al. [11] researched the reduction of carbon-bearing pellets, using the reducing agents prepared from carbonization products of rice husk, peanut shells, and wood chips. The result showed that the carbon-bearing pellets could be reduced rapidly between $1473 \mathrm{~K}$ and $1573 \mathrm{~K}$ in about 15 to 20 minutes, while the higher carbon content and appropriate volatile content in biological carbon were beneficial to the pellet reduction. Han et al. [12] studied the effect of biomass on the reduction of carbon-bearing pellets using charcoal, bamboo charcoal, and straw as reductant. The results showed that 
TABLE 1: Chemical composition of iron ore (wt\%).

\begin{tabular}{cccccccc}
\hline TFe & $\mathrm{FeO}$ & $\mathrm{SiO}_{2}$ & $\mathrm{Al}_{2} \mathrm{O}_{3}$ & $\mathrm{CaO}$ & $\mathrm{MgO}$ & $\mathrm{P}$ & \\
\hline 61.4 & 23.5 & 3.3 & 1.1 & 1.0 & 0.2 & 0.028 & 0.328 \\
\hline
\end{tabular}

TABLE 2: Proximate analysis of reducing agent (wt\%).

\begin{tabular}{lcccrr}
\hline Type of reducing agent & Fixed carbon & Ash & Volatile matter & P & S \\
\hline Anthracite & 78.8 & 13.4 & 7.9 & 0.024 & 0.580 \\
Cow dung & 7.7 & 24.9 & 67.4 & 0.001 & 0.270 \\
\hline
\end{tabular}

TABLE 3: Raw material ratio of the carbon-bearing iron ore pellets.

\begin{tabular}{lccccc}
\hline Sample number & Iron ore & Anthracite & Cow dung & Bentonite & $\mathrm{C}_{\text {fix }} / \mathrm{O}_{\text {iron oxide }}$ \\
\hline 1 & $82.5 \%$ & $17.5 \%$ & $0.0 \%$ & $1.6 \%$ & 1.0 \\
2 & $79.4 \%$ & $16.5 \%$ & $4.1 \%$ & $1.6 \%$ & 1.0 \\
3 & $76.7 \%$ & $15.6 \%$ & $7.8 \%$ & $1.6 \%$ & 1.0 \\
4 & $74.2 \%$ & $14.7 \%$ & $11.1 \%$ & $1.6 \%$ & 1.0 \\
5 & $72.1 \%$ & $14.0 \%$ & $14.0 \%$ & $1.6 \%$ & 1.0 \\
\hline
\end{tabular}

the biomass reductants had little effect on metallisation rate, but certain biomass reductants had a substantial influence on the strength and volumetric shrinkage of the pellets. The compressive strength of pellets with straw was relatively higher, while the strength of pellets with charcoal or bamboo charcoal was low.

Biomass includes all animals, plants, and microorganisms, including organic waste residues. Thus, maximising the use of biomass could potentially relieve the global energy crisis. The large amount of animal dung produced as a byproduct of the Agricultural Industry is causing an increasingly serious environmental problem [13], with the stock of cow dung topping the list. Researchers have made extensive studies regarding the issue of cow dung utilisation. Cow dung reclamation technology, such as energy, composting, and animal feed, has achieved considerable economic and social benefits [14-17]. Other than this, researchers are also exploring the applications of cow dung in areas such as new preparation methods of biomass carbon materials [18-20] and solid waste disposal [21, 22].

Similar to other plant biomass, cellulose, hemicellulose, and lignin are the main chemical constituents of dry cow dung. The similarity of organic components between cow dung and plant biomass makes it feasible to use cow dung as an alternative reducing agent in iron ore reduction, and this has been demonstrated in various studies. Rath et al. [23] used cow dung as a reductant in the reduction roasting of an iron ore slime containing $56.2 \% \mathrm{Fe}$. A concentrate of $\sim 64 \% \mathrm{Fe}$, with a recovery of $\sim 66 \mathrm{wt} \%$, was obtained from the reduced product after being subjected to low intensity magnetic separation. Under similar conditions, a concentrate of $\sim 66 \% \mathrm{Fe}$, with a recovery of only $35 \mathrm{wt} \%$, was obtained after using conventional charcoal as the reductant $(93.5 \%$ fixed carbon and $1.2 \%$ volatile matter), which demonstrated that cow dung was a better reductant.

The key purpose of this study is to investigate the effect of cow dung addition on the strength of carbon-bearing iron ore pellets and its mechanism. The influence of cow dung addition on the quality of green and dry pellets is evaluated based on FTIR analysis, and the mechanism of strength variation of reduction roasted pellets was investigated by analysing the phase composition and microstructure using XRD and SEM, to provide a benchmark for further utilisation of cow dung in direct-reduction ironmaking.

\section{Materials and Methods}

2.1. Materials. Carbon-bearing iron ore pellets were prepared by pressing a mixture consisting of iron ore, anthracite, bentonite, and different proportions of cow dung. The chemical composition of the iron ore used in this study is shown in Table 1, while the proximate analyses of the anthracite and the cow dung used as the reductant in this study are given in Table 2. The cow dung was obtained from the Mengniu Modern Animal Husbandry (Group), Maanshan Co. First, all of the raw materials were dried at $383 \mathrm{~K}$ for $24 \mathrm{~h}$, individually ground in a ball mill to a passing size of $74 \mu \mathrm{m}$ for the iron ore and $200 \mu \mathrm{m}$ for the reducing agents. Mixtures of the ground materials were prepared according to the experimental plan given in Table 3. A little water was added, and $20 \mathrm{~mm}$ diameter pellets (molar ratio of $\mathrm{C}_{\mathrm{fix}} / \mathrm{O}_{\text {iron oxide }}=$ 1) were prepared by pressing at $10 \mathrm{MPa}$.

2.2. Characterization Techniques. Characterization studies were undertaken on the raw materials and some reduction roasted products. The FTIR spectra were obtained with a Nicolet 8700 spectrophotometer by adding 32 scans at a resolution of $4 \mathrm{~cm}^{-1}$, using $\mathrm{KBr}$ wafers containing about $0.5 \mathrm{~g}$ of sample, which had been dried at $393 \mathrm{~K}$ for $24 \mathrm{~h}$ before spectral analysis. XRD was carried out with a D8 Advance $\mathrm{X}$-ray powder diffractometer using $\mathrm{Cu}-\mathrm{K} \alpha$ radiation. The voltage and current of the machine were set at $60 \mathrm{kV}$ and $80 \mathrm{~mA}$, respectively, scanning from $20^{\circ}$ to $80^{\circ}$ using a step size of $0.02^{\circ}$. A scanning electron microscope (NOVA Nano SEM430, USA) equipped with EDS detector was used for the microstructure studies. 


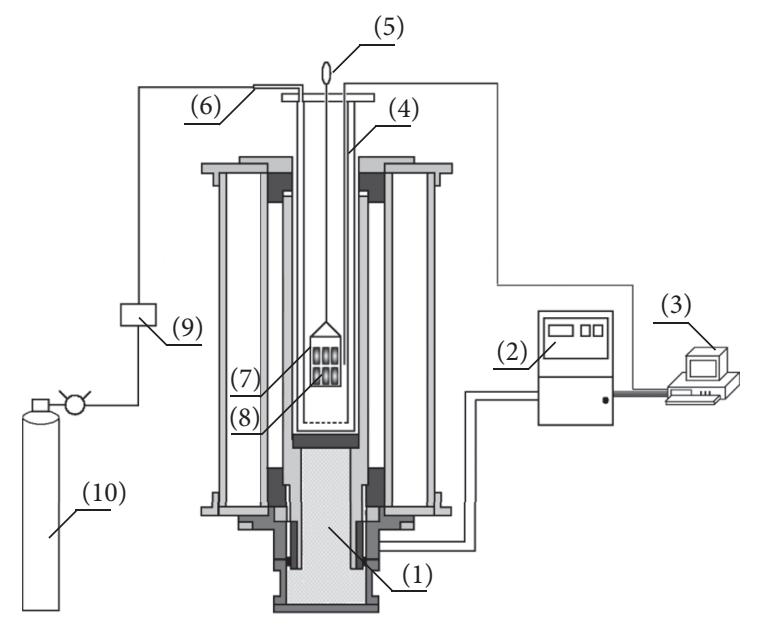
(1) Tubular furnace
(2) Temperature control panel
(3) Integrated console
(4) Thermocouple
(5) Hanging hook

(6) Inlet pipe

(7) $\mathrm{Ni}-\mathrm{Cr}$ basket

(8) Carbon-bearing pellets

(9) Mass flow controller

(10) Nitrogen gas

FIGURE 1: A schematic of experimental apparatus of reduction roasting.

2.3. Strength Tests and Reduction Roasting. The compressive strength of green, dry, and reduction roasted pellets was measured with an automatic compressive strength tester, and each sample was tested 20 times under the same conditions and the results were averaged. A schematic of the reduction roasting experimental apparatus is shown in Figure 1. The furnace has a working temperature range of 298-1573 K, with $\pm 1 \mathrm{~K}$ temperature control accuracy, and produces a $150 \mathrm{~mm}$ hot zone. The carbon-bearing pellets were placed in a Ni$\mathrm{Cr}$ alloy basket which was hung over the hot zone, and the pellets were heated to $1523 \mathrm{~K}$ at a rate of $20 \mathrm{~K} / \mathrm{min}$. Highpurity nitrogen gas was supplied at a constant flowrate of $11 /$ min in the reaction tube. At the end of the experiment, the basket was quickly moved to the top of the furnace with highpurity nitrogen gas continuing to be supplied until the pellets cooled to room temperature.

\section{Results and Discussion}

3.1. Effects of Treated Cow Dung Addition on the Cold Strength of Carbon-Bearing Pellets. The cold strength test results of green and dry pellets with different proportions of cow dung addition are shown in Figure 2. The bar charts show that the strength of green and dry pellets varies with cow dung addition, but there is no clear correlation between the average compressive strength and the ratio of cow dung to anthracite added. The average strength of the green pellets containing cow dung decreased by $8-16 \%$ relative to pellets with no dung. For example, the strength of green pellets with no dung was $10.1 \mathrm{~N} /$ pellet, while green pellets with a dung-to-anthracite ratio of $1: 4$ (containing $4.1 \%$ cow dung) were $8.5 \mathrm{~N} /$ Pellet and the strength of green pellets with a dung-to-anthracite ratio of $3: 4$ (containing $11.1 \%$ cow dung) was $8.6 \mathrm{~N} /$ Pellet. In contrast, the average strength of dry pellets containing cow dung was between $33.5 \%$ and $56.6 \%$ higher than dry pellets with no cow dung. For example, the average strength of dry pellets with no cow dung was $18.2 \mathrm{~N} /$ pellet, while pellets with a dung-to-anthracite ratio of $1: 4$ had an average strength of 27.7 N/pellet.

The FTIR spectral analyses of different pellet samples are provided in Figure 3, which shows that the spectrum of the iron ore-anthracite sample (Figure 3(a)) aligns closely with the spectrum of the iron ore-anthracite-bentonite sample (Figure 3(b)). The main absorption peaks appear at $3413 \mathrm{~cm}^{-1}$ (stretching vibration centre of hydroxy-OH), $1619 \mathrm{~cm}^{-1}$ (antisymmetric vibration peak of carboxyl-COOH) and $1032 \mathrm{~cm}^{-1}$ ( $\mathrm{Si}-\mathrm{O}$ bond stretching vibration of silicate impurities). This demonstrates that bentonite is not chemically adsorbed with the raw materials such as iron ore and anthracite, and it can be assumed that the strength of these green pellets with no cow dung was maintained by alternative strength mechanisms such as capillary and viscous forces.

A SEM backscattered image of a cross-sectioned dry pellet sample with no added cow dung is shown in Figure 4(a). The bentonite, iron concentrate, and finely pulverised coal particles have formed a gel, which has surrounded or coated the particles. The gel has a bridging effect and increases the bridge fluid viscosity and surface tension, strengthening the capillary and viscous forces that bind the particles in the green pellets [24]. In the drying process, the bentonite can make the solid particles be further drawn by the gel, the area of particle contact be increased, the intermolecular forces be strengthened, and the strength of the dry pellet be improved [25].

The FTIR spectra of a pellet sample containing anthracite, iron ore, and cow dung are shown in Figure 3(c), while a pellet sample containing anthracite, iron ore, cow dung, and bentonite is shown in Figure 3(d). The main absorption peaks in Figure 3(c) appear at $3423 \mathrm{~cm}^{-1}, 1631 \mathrm{~cm}^{-1}, 1423 \mathrm{~cm}^{-1}$, and $1032 \mathrm{~cm}^{-1}$, while the main peaks in Figure 3(d) appear at $3420 \mathrm{~cm}^{-1}, 1633 \mathrm{~cm}^{-1}$, and $1032 \mathrm{~cm}^{-1}$. The stretching vibration peak of hydroxy-OH and antisymmetric peak of carboxyl-COOH have shifted and increased in intensity. Near $1423 \mathrm{~cm}^{-1}$, the lignin double bond or the hydroxy of carboxylic acid has generated an in-plane bending vibration peak, which suggests that chemical adsorption has probably occurred between the cellulose, hemicellulose, and free hydroxy of lignin and iron ore.

A SEM backscattered image of a cross-sectioned dry pellet sample containing $14.0 \%$ cow dung is shown in Figure 4(b). It can be seen in the figure that the bentonite, iron ore, and finely pulverised coal have formed a gel, infilled with or coating, particles, similar to that observed in the sample that did not contain cow dung (Figure 4(a)). The cellulose and hemicellulose in the particles of cow dung have a rope-shaped arrangement that reinforces the structure of the dry pellets and results in greater strength compared with the dry pellets that did not contain any cow dung. 


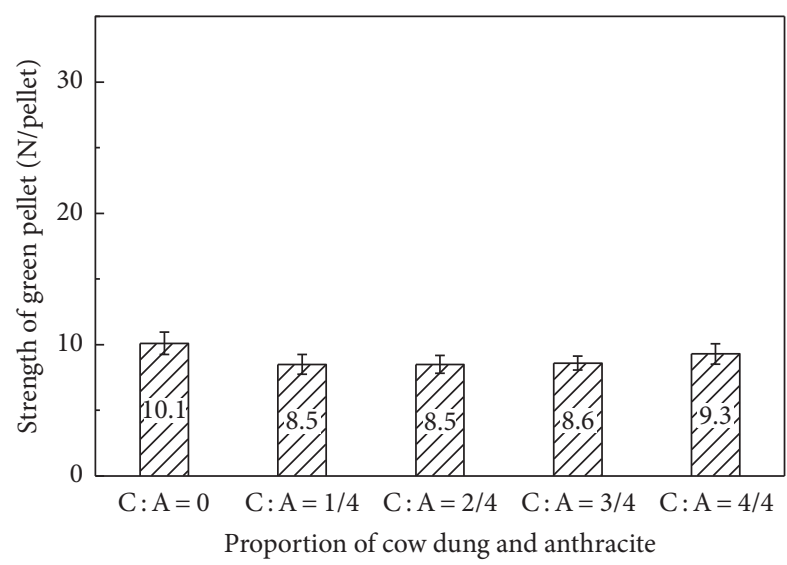

(a)

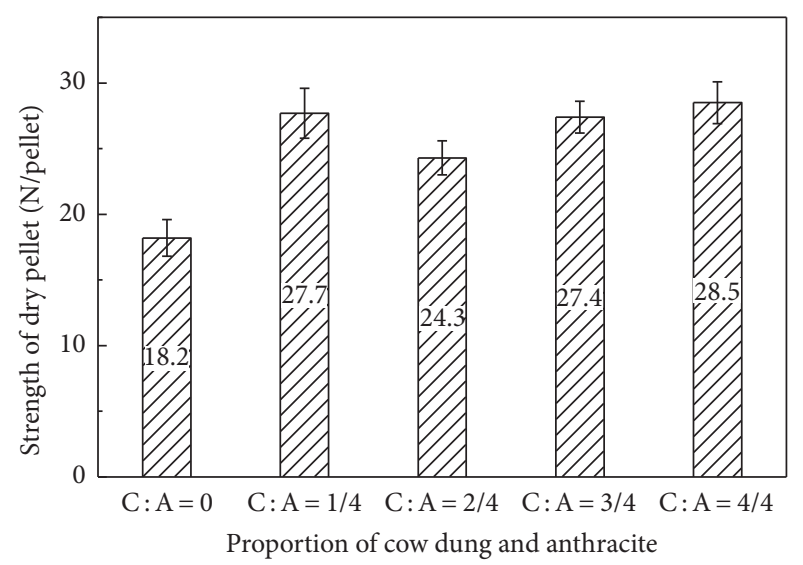

(b)

FIGURE 2: Cold strength of carbon-bearing pellets with different proportions of cow dung. (a) Green pellet; (b) dry pellet.

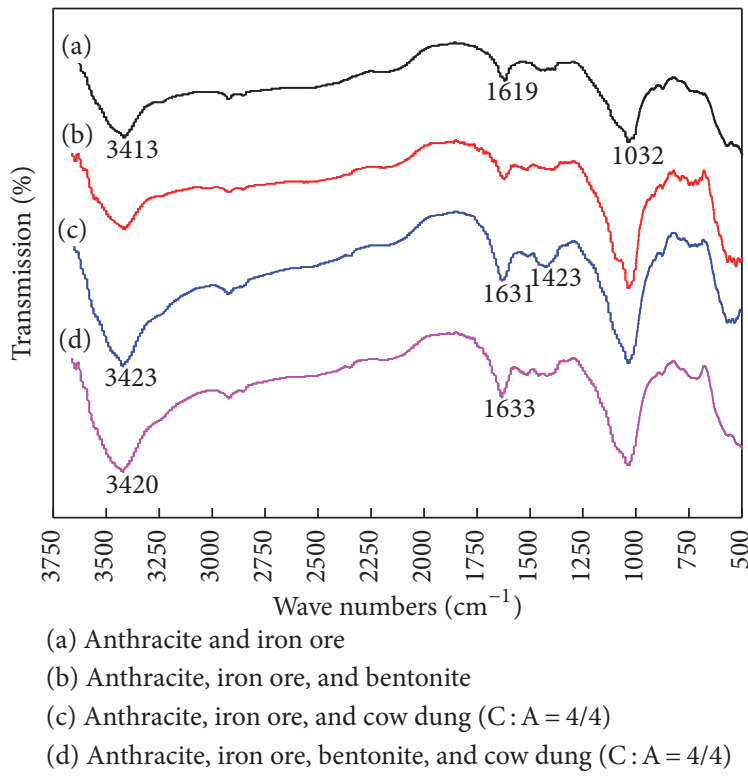

FIGURE 3: FTIR spectra of carbon-bearing pellets, comparing different raw materials.

3.2. Effects of Treated Cow Dung Addition on the Strength of Carbon-Bearing Pellets after Reduction Roasting. The average strength of pellets that contained different proportions of cow dung after reduction roasting at $1523 \mathrm{~K}$ is given in Figure 5. The bar chart shows that the strength of the roasted sample with no cow dung was $2473 \mathrm{~N} /$ pellet. The pellets that had cow dung additive had a higher strength, but the strength decreased with increasing cow dung addition. The pellets containing $4.1 \%$ cow dung had a strength of $3106 \mathrm{~N} /$ pellet after reduction roasting, which was the highest strength obtained (an increase of 25.6\%).

The strength of reduction roasted pellets is controlled by the rate of formation of intergrown iron crystals, their abundance, and physical structure, while the bentonite binder will have little effect on pellet strength after roasting [26]. When a mixture of anthracite and cow dung is used as a
TABLE 4: Degree of metallization of carbon-bearing pellets after reduction roasting (\%).

\begin{tabular}{lccc}
\hline Sample number & Total Fe & Metal Fe & $R_{m}$ \\
\hline 1 & 81.9 & 71.0 & 86.7 \\
2 & 79.6 & 70.5 & 88.6 \\
3 & 78.0 & 67.6 & 86.6 \\
4 & 76.4 & 62.6 & 82.0 \\
5 & 74.9 & 60.1 & 80.3 \\
\hline
\end{tabular}

reducing agent in carbon-bearing pellets, the volatile matter in the cow dung cracks at about $773 \mathrm{~K}$ and will produce $\mathrm{H}_{2}$, $\mathrm{CO}, \mathrm{CO}_{2}, \mathrm{CH}_{4}$, and other gases [27]. Reduction reactions may occur directly between $\mathrm{H}_{2}, \mathrm{CO}$, and $\mathrm{CH}_{4}$, while $\mathrm{CO}$ (which is a strong reductive agent) will be formed according to the Boudouard reaction between $\mathrm{C}$ (originating from the anthracite and cow dung additives) and $\mathrm{CO}_{2}$. Devolatilisation generates pores within the carbon-bearing pellets, which increases their permeability to the reducing gases, promoting the rate of reduction and formation of intergrown iron crystals.

The size of the carbon-bearing pellets before and after reduction roasting is compared in Figure 6, which shows that the diameter of the sample with no cow dung contracted by $19 \%$, and the sample with $7.8 \%$ cow dung contracted by $24 \%$, while the sample containing $14.0 \%$ cow dung contracted by $28 \%$. Thus, it can be concluded that the pellet shrinkage increases with increasing cow dung content. The shrinkage of reduction roasted pellets is mainly the result of aggregation of intergrown iron crystals, but porosity and the amount of low melting-point slag present may also influence the extent of pellet shrinkage [28]. However, Figures 5 and 6 show that the pellet shrinkage does not clearly correlate with higher pellet strength.

The metallisation degree of carbon-bearing pellets after reduction is shown in Table 4. It can be seen that the metal produced of reduction sample gradually decreases with increase of amount of the cow dung. The pellets containing $4.1 \%$ cow dung had a degree of metallisation of $88.6 \%$ 


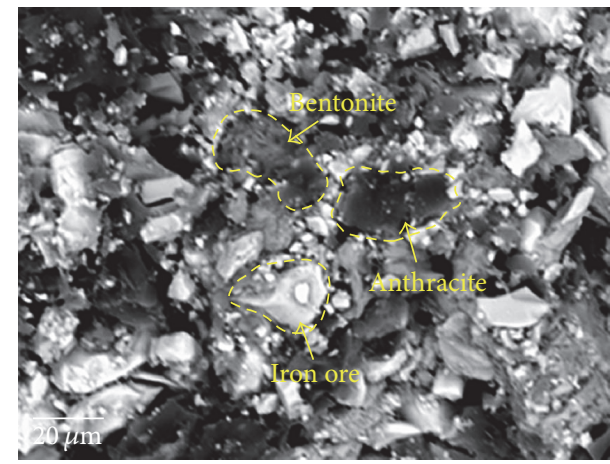

(a)

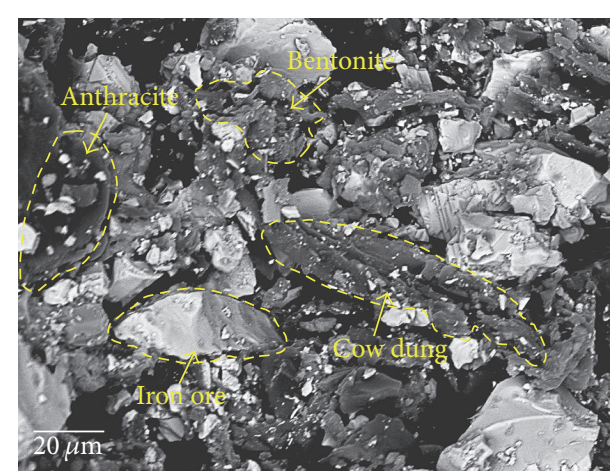

(b)

FIGURE 4: SEM back scattered images of different carbon-bearing pellets after drying. (a) Dry pellet sample without cow dung; (b) dry pellet sample with $14.0 \%$ cow dung.

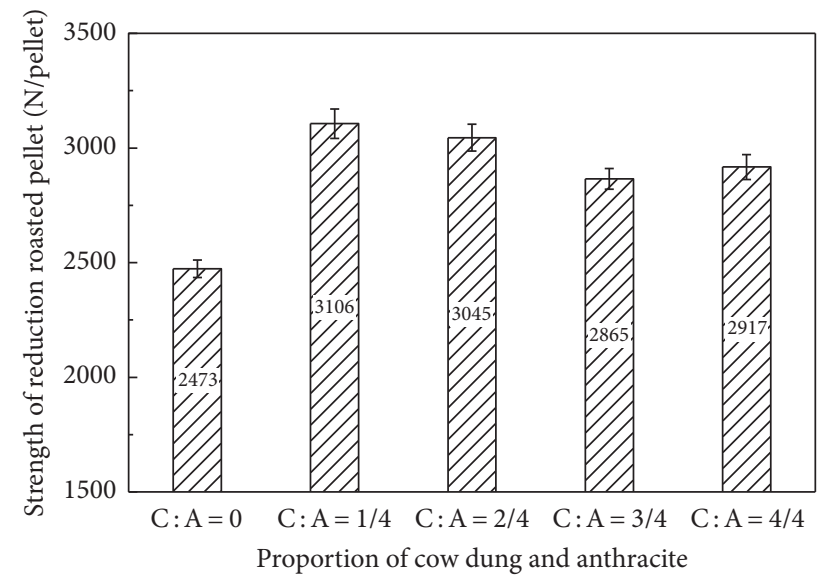

Figure 5: Strength of different carbon-bearing pellets after reduction roasting at $1523 \mathrm{~K}$.

after reduction roasting, which was the highest degree of metallisation obtained.

\subsection{Phase Analysis of Carbon-Bearing Pellets after Reduction} Roasting. Figure 7 shows the XRD spectra of different pellet samples after reduction roasting at temperatures of 873, 1073, 1273 , and $1523 \mathrm{~K}$. It can be seen in Figure 7 (a) that, after roasting at $873 \mathrm{~K}$, the sample containing no cow dung additive was mainly composed of magnetite $\left(\mathrm{Fe}_{3} \mathrm{O}_{4}\right)$ and a small amount of hematite $\left(\alpha-\mathrm{Fe}_{2} \mathrm{O}_{3}\right)$ and maghemite $\left(\gamma-\mathrm{Fe}_{2} \mathrm{O}_{3}\right)$. In comparison, the peak intensity of $\alpha-\mathrm{Fe}_{2} \mathrm{O}_{3}$ is smaller, while the peak intensity of $\mathrm{Fe}_{3} \mathrm{O}_{4}$ is larger, in the sample that originally contained $7.8 \%$ cow dung. When this sample $(7.8 \%$ cow dung) was reduction roasted at $1073 \mathrm{~K}$, diffraction peaks for wüstite $(\mathrm{FeO})$ appeared, while the diffraction peaks of $\mathrm{Fe}_{2} \mathrm{O}_{3}$ were no longer detected (Figure 7(b)). After reduction roasting at $1273 \mathrm{~K}$, diffraction peaks for metallic Fe were present, and their intensity was stronger in the sample with $7.8 \%$ cow dung compared to the sample with no cow dung (Figure $7(\mathrm{c})$ ). Following reduction roasting at $1523 \mathrm{~K}$, the XRD spectrum of the sample initially containing $7.8 \%$ cow dung consisted mainly of Fe diffraction peaks (Figure $7(\mathrm{~d})$ ).
The results in Figure 7 demonstrated that cow dung addition and reduction temperature affect the extent of reduction of the iron oxides in the pellets. Taking into account the degree of metallisation in Table 4, it can be concluded that the extent of reduction at $1523 \mathrm{~K}$ decreases when the amount of cow dung additive exceeds about $4-8 \%$.

SEM backscattered images of different carbon-bearing pellet samples reduction roasted at 1273 and $1523 \mathrm{~K}$ are shown in Figure 8. Figure 8(a) shows that the edges of iron ore particles were blurred and boundaries between some of the ore and reducing agent particles were hard to distinguish in the sample that had no cow dung addition after roasting at $1273 \mathrm{~K}$. There were few small particles of reducing agent observed, and the structure of the pellet was relatively loose. For the sample with $7.8 \%$ cow dung (Figure $8(\mathrm{~b})$ ), whole iron ore particles were hard to distinguish, while some metallic iron had formed on the surface of some iron ore and reducing agent particles. The microstructure of the roasted samples that contained $7.8 \%$ and $14.0 \%$ cow dung (Figures 8(b) and 8(c)) was relatively similar. After reduction roasting at $1523 \mathrm{~K}$, the discrete particles of iron ore, reducing agent, and other raw materials disappeared (Figures $8(\mathrm{~d})-8(\mathrm{f}))$, and the reduction product was predominantly metallic iron with a minor amount of iron oxide. In the sample with no added cow dung (Figure 8(d)), the metallic iron phase is connected by a number of fine grains and there are a considerable number of pores or voids in the pellets. The metallic iron in the samples with $7.8 \%$ and $14.0 \%$ cow dung is flaky, but the sample with $14.0 \%$ cow dung has more voids and the amount of solid solution formed by the metallic iron and incompletely reduced iron oxide is more abundant.

Figures 7 and 8 demonstrate the effect of cow dung addition and the influence of temperature on the microstructure and phase composition of reduction roasted pellets. After reduction roasting at $1523 \mathrm{~K}$, the intergrown iron crystals in pellets that contained cow dung are strongly clustered compared with the samples containing no cow dung. The higher ash content of the cow dung compared to the anthracite can improve the quaternary basicity (mass ratio of $\left.(\mathrm{CaO}+\mathrm{MgO}) /\left(\mathrm{SiO}_{2}+\mathrm{Al}_{2} \mathrm{O}_{3}\right)\right)$ of the carbon-bearing pellets, 


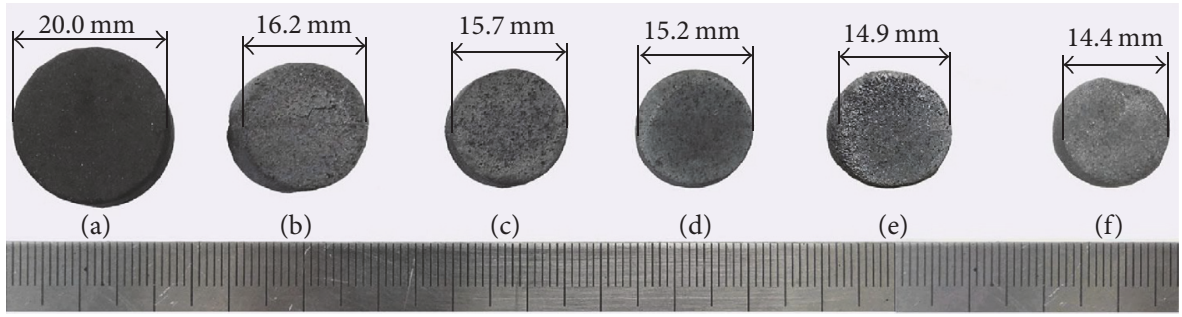
(a) Original sample
(d) Cow dung $7.8 \%$
(b) Cow dung $0 \%$
(e) Cow dung $11.1 \%$
(c) Cow dung $4.1 \%$
(f) Cow dung $14.0 \%$

FIGURE 6: Size of the carbon-bearing pellets before and after reduction roasting.
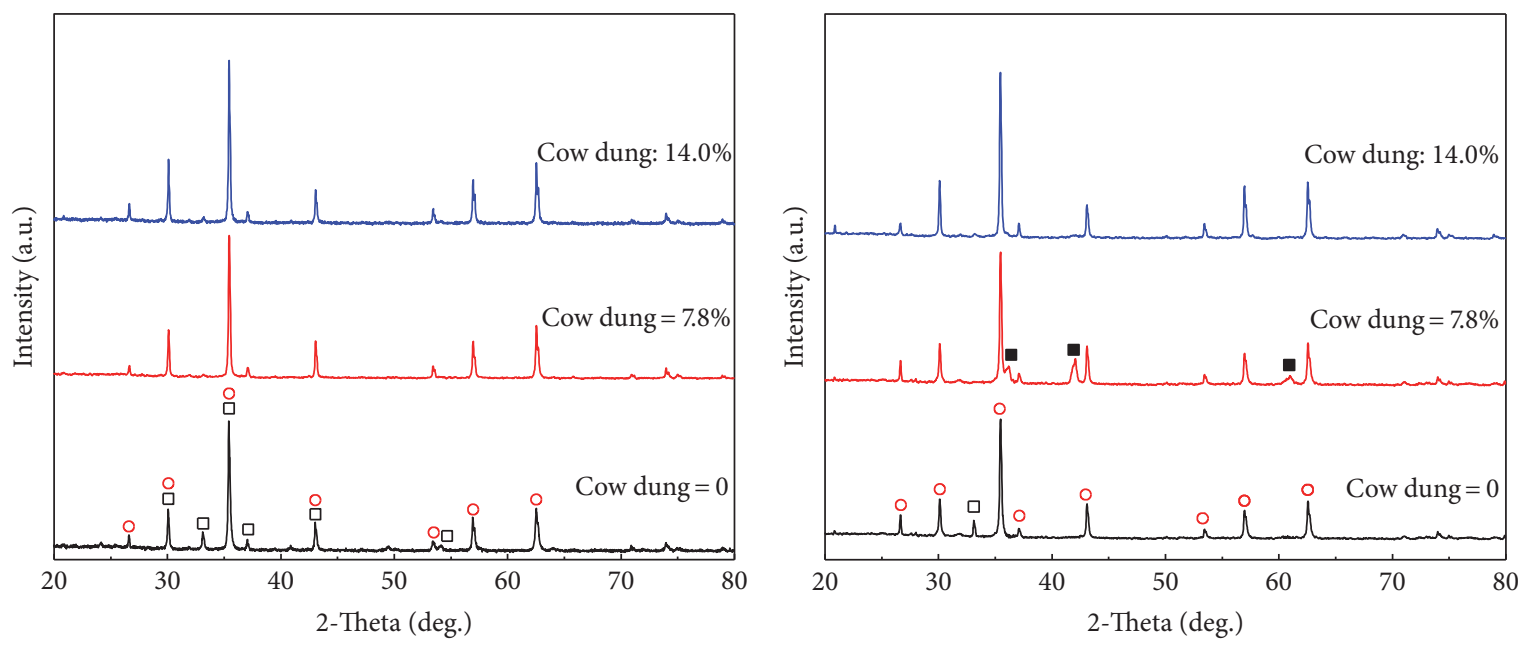

ㅁ $\mathrm{Fe}_{2} \mathrm{O}_{3}$

ㅁ $\mathrm{Fe}_{2} \mathrm{O}_{3}$

- $\mathrm{Fe}_{3} \mathrm{O}_{4}$

- $\mathrm{FeO}$

(a)

(b)
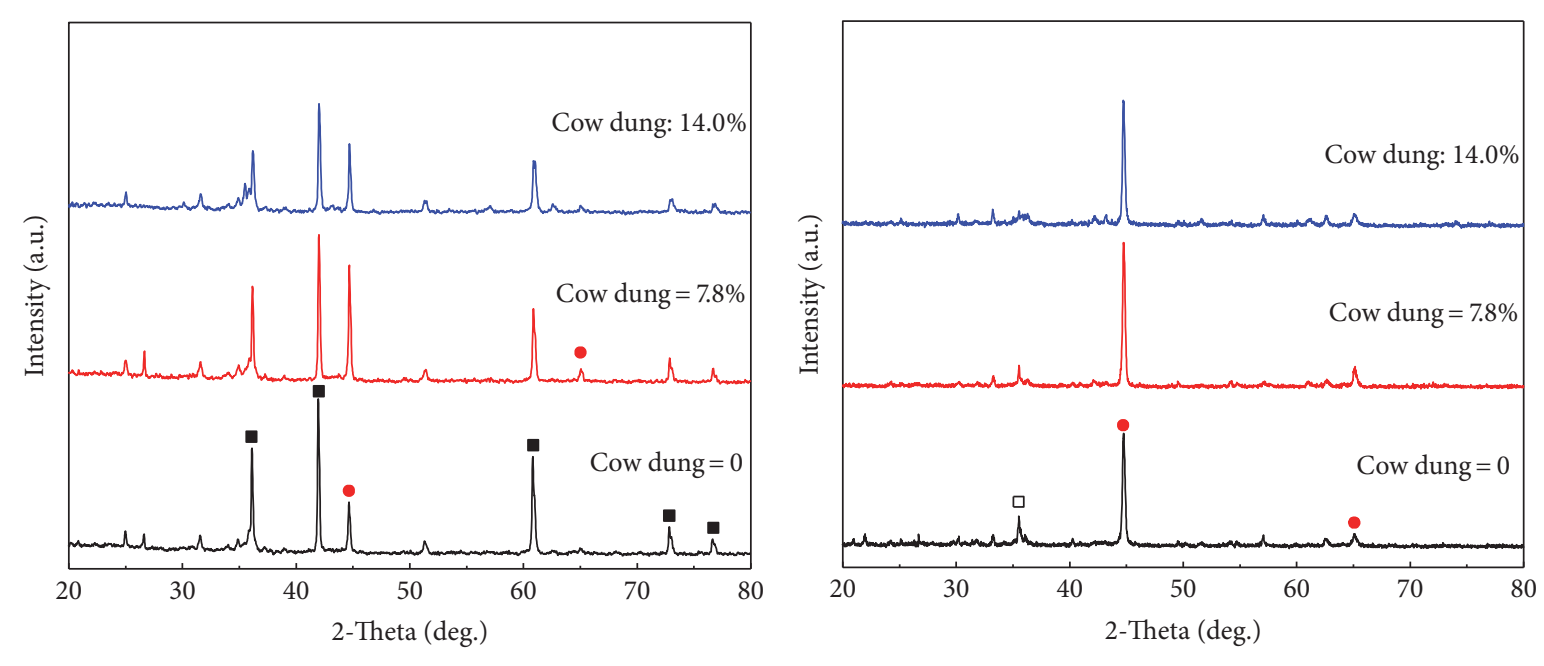

- $\mathrm{FeO}$

$\square \mathrm{Fe}_{2} \mathrm{O}_{3}$

- $\mathrm{Fe}$

(c)

(d)

FIGURE 7: XRD of different carbon-bearing pellets after reduction at different temperatures. (a) $873 \mathrm{k}$; (b) $1073 \mathrm{k}$; (c) $1273 \mathrm{k}$; (d) $1523 \mathrm{k}$. 


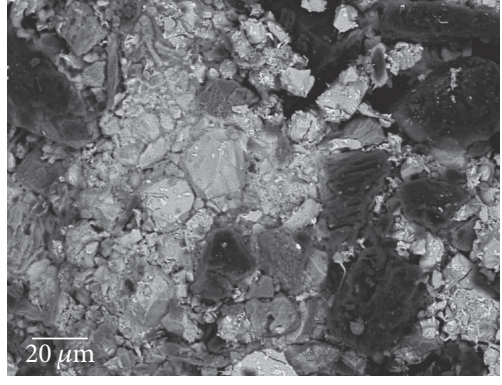

(a)

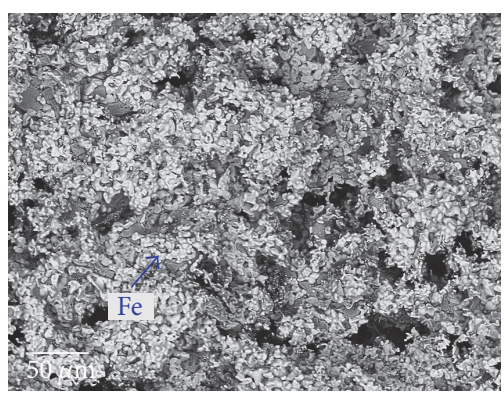

(d)

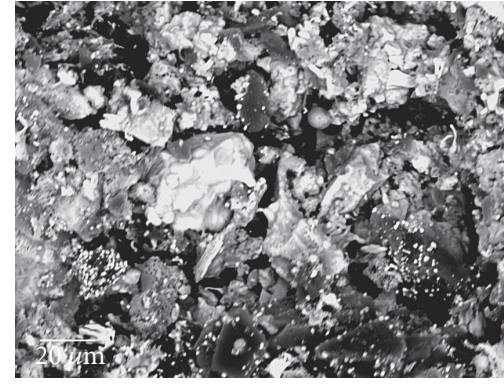

(b)

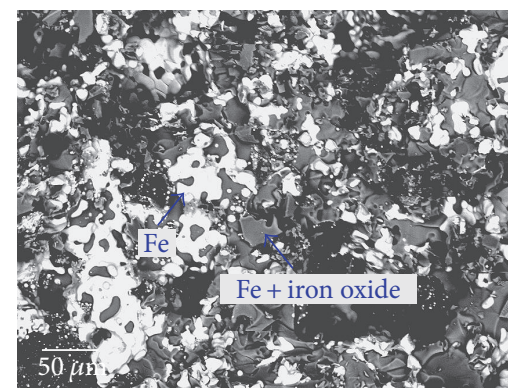

(e)

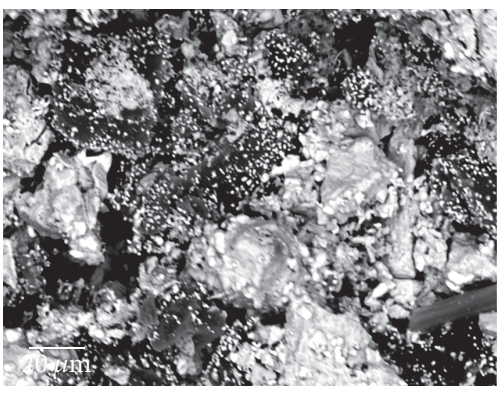

(c)

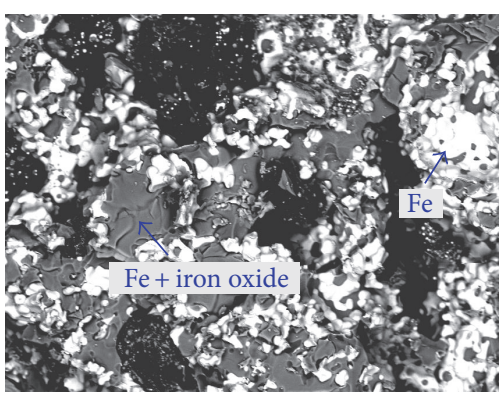

(f)

FIGURE 8: SEM backscattered images of different carbon-bearing pellets after reduction at 1273 and $1523 \mathrm{~K}$. (a) $1273 \mathrm{k}$, cow dung $0 \%$; (b) $1273 \mathrm{k}$, cow dung 7.8\%; (c) $1273 \mathrm{k}$, cow dung $14.0 \%$; (d) $1523 \mathrm{k}$, cow dung $0 \%$; (e) $1523 \mathrm{k}$, cow dung $7.8 \%$; (f) $1523 \mathrm{k}$, cow dung $14.0 \%$.

promoting the reduction of iron oxides and facilitating the aggregation of intergrown iron crystals [29]. The larger amount of low melting-point amorphous slag produced can infill the pores, making the structure of the pellets stronger and more compact after reduction. However, an excessive addition of cow dung (of more than about 4-8\%) will lead to more voids caused by hydrocarbon cracking and volatilisation, which will decrease the extent of metallisation during the reduction of iron oxides, resulting in a decrease pore filling by amorphous slag phases as well as decrease roasted pellet strength, compared with pellets that contained about $4 \%$ cow dung.

\section{Conclusions}

The following conclusions can be made through this study.

(1) The addition of cow dung affects the strength of carbon-bearing pellets. The green pellet strength decreased by about $8-16 \%$ and the dry strength increased by about $34-57 \%$ after adding cow dung. However, there was no obvious correlation between the quantity of cow dung added and the change in cold pellet strength. Compared with reduction roasted pellets containing no cow dung, roasted pellets containing cow dung had greater strength (ranging from about $16-26 \%$ stronger), but the strength decreased as the proportion of cow dung increased.

(2) The lower strength of green pellets containing cow dung was found to be due to expansion of the amorphous region of the cellulose contained in the cow dung. The greater strength of dry pellets containing cow dung was found to be the result of chemical adsorption among cellulose, hemicellulose, and free hydroxy in lignin and iron concentrate.
The rope arrangement of cellulose and hemicellulose also positively reinforces the pellet structure.

(3) In process of reduction roasting of carbon-bearing pellets, cow dung additions is beneficial for aggregation of intergrown iron crystals and may help to increase the density of the physical structure of the pellets; thus the strength of the reduction roasted pellets is also improved. However, excessive addition of more than about $4-8 \%$ cow dung will result in lower pellet density and decreased strength compared with pellets containing about $4 \%$ cow dung.

\section{Conflicts of Interest}

The authors declare that they have no conflicts of interest.

\section{Acknowledgments}

The authors would like to acknowledge the funding from the Natural Science Foundation of China (Project no. 51574002).

\section{References}

[1] G. Q. Xu, "Newest advances and development prospect of COREX technology," Ironmaking, vol. 23, no. 2, pp. 50-55, 2004.

[2] W.-K. Lu and D. F. Huang, "The evolution of ironmaking process based on coal-containing iron ore agglomerates," ISIJ International, vol. 41, no. 8, pp. 807-812, 2001.

[3] S. L. Liu and C. G. Bai, "Technology research and development trend of direct reduction," Journal of Iron and Steel Research, vol. 23, no. 3, pp. 1-5, 2011. 
[4] R. Wei, L. Zhang, D. Cang, J. Li, X. Li, and C. C. Xu, "Current status and potential of biomass utilization in ferrous metallurgical industry," Renewable \& Sustainable Energy Reviews, vol. 68, pp. 511-524, 2017.

[5] Y. Ueki, R. Yoshiie, I. Naruse et al., "Reaction behavior during heating biomass materials and iron oxide composites," Fuel, vol. 104, pp. 58-61, 2013.

[6] G. Fick, O. Mirgaux, P. Neau, and F. Patisson, "Using biomass for pig iron production: A technical, environmental and economical assessment," Waste and Biomass Valorization, vol. 5, no. 1, pp. 43-55, 2014.

[7] M. Gan, X. Fan, X. Chen et al., "Reduction of pollutant emission in iron ore sintering process by applying biomass fuels," ISIJ International, vol. 52, no. 9, pp. 1574-1578, 2012.

[8] T. Kawaguchi and M. Hara, "Utilization of biomass for iron ore sintering," ISIJ International, vol. 53, no. 9, pp. 1599-1606, 2013.

[9] V. Strezov, "Iron ore reduction using sawdust: Experimental analysis and kinetic modelling," Journal of Renewable Energy, vol. 31, no. 12, pp. 1892-1905, 2006.

[10] R. Wei, D. Cang, Y. Bai, D. Huang, and X. Liu, "Reduction characteristics and kinetics of iron oxide by carbon in biomass," Ironmaking and Steelmaking, vol. 43, no. 2, pp. 144-152, 2016.

[11] Z. L. Liu, F. L. Wang, J. L. Wang, Z. P. Gao, and H. H. Liu, "Study on the Reduction Process of Carbon-Bearing Pellets from Agricultural Waste," Journal of Hunan University of Technology, vol. 28, no. 1, pp. 87-92, 2014.

[12] H. Han, P. Yuan, D. Duan, and D. Li, "Application of biomass to the RHF direct reduction process," Chongqing Daxue Xuebao/Journal of Chongqing University, vol. 38, no. 5, pp. 164-170, 2015.

[13] W. Li, M. Xu, and J. Li, "Prospect of resource utilization of animal faeces wastes," Nongye Jixie Xuebao/Transactions of the Chinese Society for Agricultural Machinery, vol. 44, no. 5, pp. 135-140, 2013.

[14] J. Liu, S. Wang, Q. Wei, and S. Yan, "Present situation, problems and solutions of China's biomass power generation industry," Energy Policy, vol. 70, pp. 144-151, 2014.

[15] S. Zhou, Y. Zhang, and Y. Dong, "Pretreatment for biogas production by anaerobic fermentation of mixed corn stover and cow dung," Energy, vol. 46, no. 1, pp. 644-648, 2012.

[16] T. Karak, I. Sonar, R. K. Paul et al., "Composting of cow dung and crop residues using termite mounds as bulking agent," Bioresource Technology, vol. 169, pp. 731-741, 2014.

[17] A. Kumar, N. Kumar, P. Baredar, and A. Shukla, "A review on biomass energy resources, potential, conversion and policy in India," Renewable \& Sustainable Energy Reviews, vol. 45, pp. 530-539, 2015.

[18] K. S. Ro, K. B. Cantrell, and P. G. Hunt, "High-temperature pyrolysis of blended animal manures for producing renewable energy and value-added biochar," Industrial \& Engineering Chemistry Research, vol. 49, no. 20, pp. 10125-10131, 2010.

[19] D. Bhattacharjya and J.-S. Yu, "Activated carbon made from cow dung as electrode material for electrochemical double layer capacitor," Journal of Power Sources, vol. 262, pp. 224-231, 2014.

[20] P. Vijayaraghavan, S. G. Prakash Vincent, and G. S. Dhillon, "Solid-substrate bioprocessing of cow dung for the production of carboxymethyl cellulase by Bacillus halodurans IND18," Waste Management, vol. 48, pp. 513-520, 2016.

[21] D. Singh and M. H. Fulekar, "Benzene bioremediation using cow dung microflora in two phase partitioning bioreactor," Journal of Hazardous Materials, vol. 175, no. 1-3, pp. 336-343, 2010 .
[22] D. D. Das, R. Mahapatra, J. Pradhan, S. N. Das, and R. S. Thakur, "Removal of $\mathrm{Cr}(\mathrm{VI})$ from aqueous solution using activated cow dung carbon," Journal of Colloid and Interface Science, vol. 232, no. 2, pp. 235-240, 2000.

[23] S. S. Rath, D. S. Rao, and B. K. Mishra, "A novel approach for reduction roasting of iron ore slime using cow dung," International Journal of Mineral Processing, vol. 157, pp. 216-226, 2016.

[24] S. K. Kawatra and S. J. Ripke, "Effects of bentonite fiber formation in iron ore pelletization," International Journal of Mineral Processing, vol. 65, no. 3-4, pp. 141-149, 2002.

[25] S. K. Kawatra and S. J. Ripke, "Laboratory studies for improving green ball strength in bentonite- bonded magnetite concentrate pellets," International Journal of Mineral Processing, vol. 72, no. 1-4, pp. 429-441, 2003.

[26] J. Li, R. Wei, H. Long, P. Wang, and D. Cang, "Sticking behavior of iron ore-coal pellets and its inhibition," Powder Technology, vol. 262, pp. 30-35, 2014.

[27] K. B. Cantrell, P. G. Hunt, M. Uchimiya, J. M. Novak, and K. S. Ro, "Impact of pyrolysis temperature and manure source on physicochemical characteristics of biochar," Bioresource Technology, vol. 107, pp. 419-428, 2012.

[28] R. F. Wei, J. X. Li, G. W. Tang, and D. Q. Cang, "Strength and consolidation mechanism of iron ore and coal pellets," Ironmaking and Steelmaking, vol. 41, no. 7, pp. 514-520, 2014.

[29] T. Miki and Y. Fujita, "Reaction between iron oxide and gangue minerals at $1373 \mathrm{~K}$ under Ar atmosphere," ISIJ International, vol. 55, no. 6, pp. 1206-1209, 2015. 

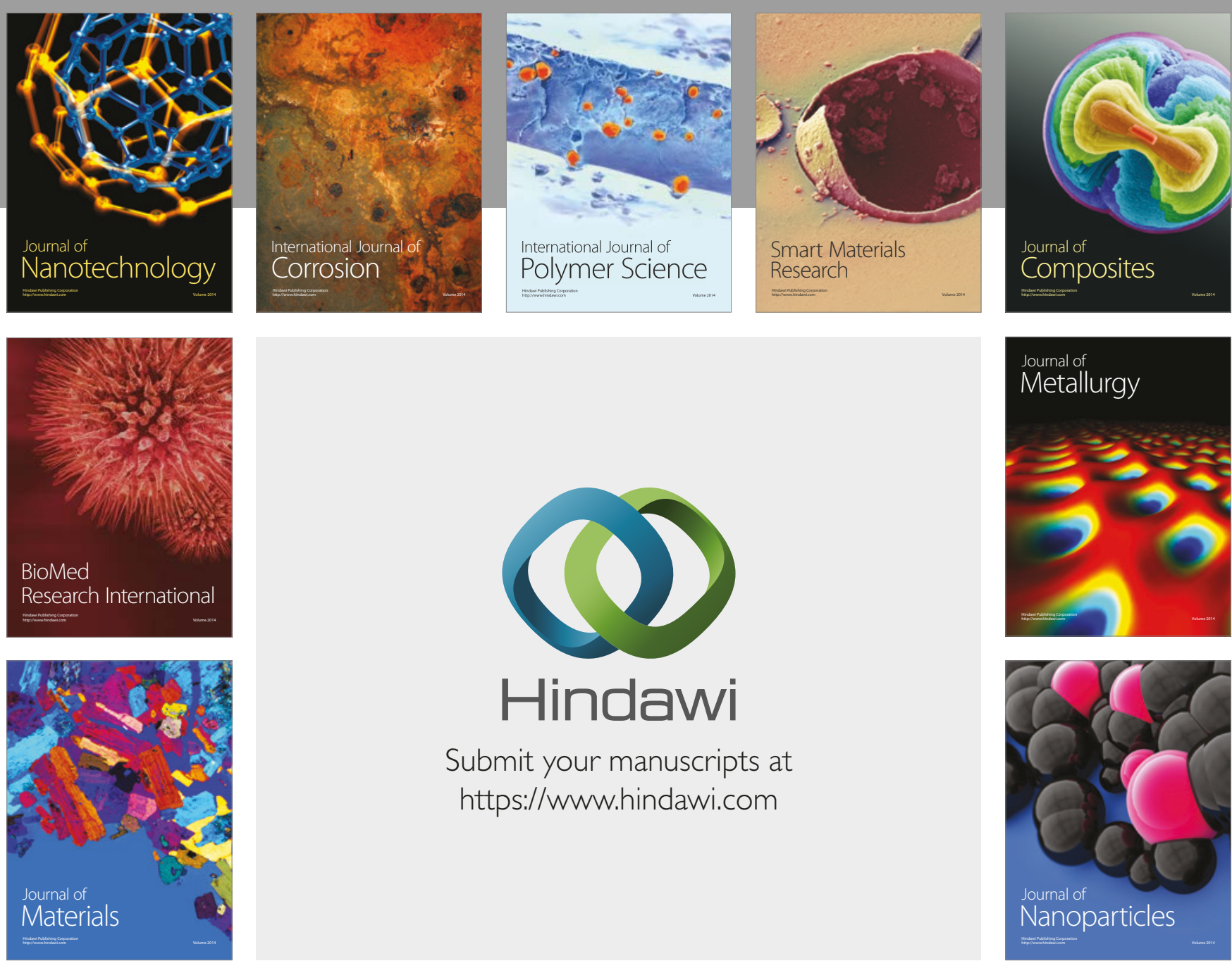

\section{Hindawi}

Submit your manuscripts at

https://www.hindawi.com
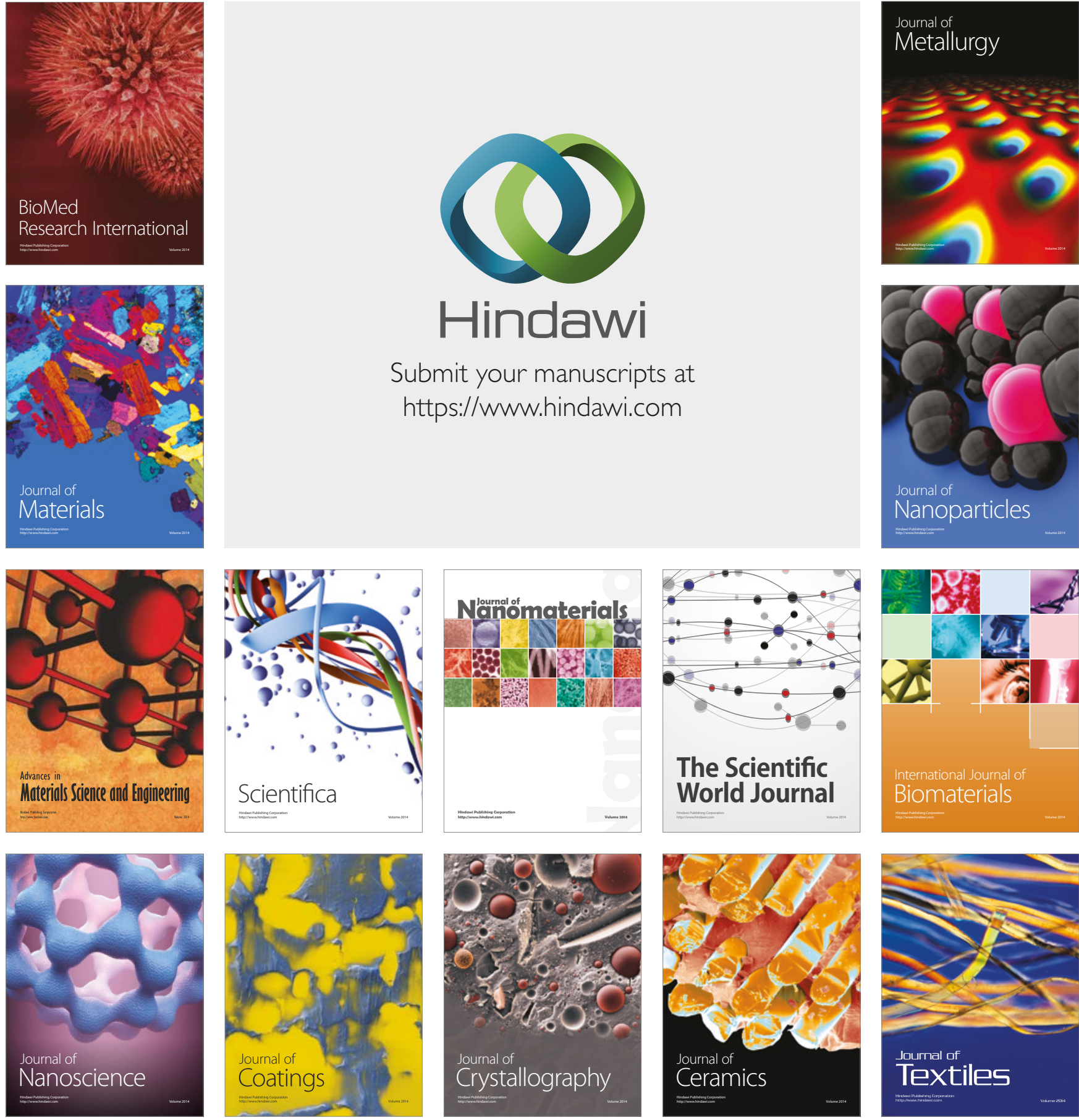

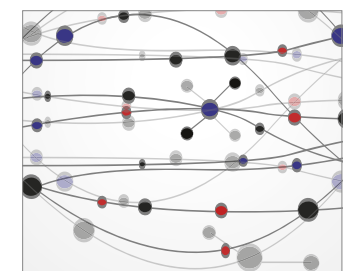

The Scientific World Journal
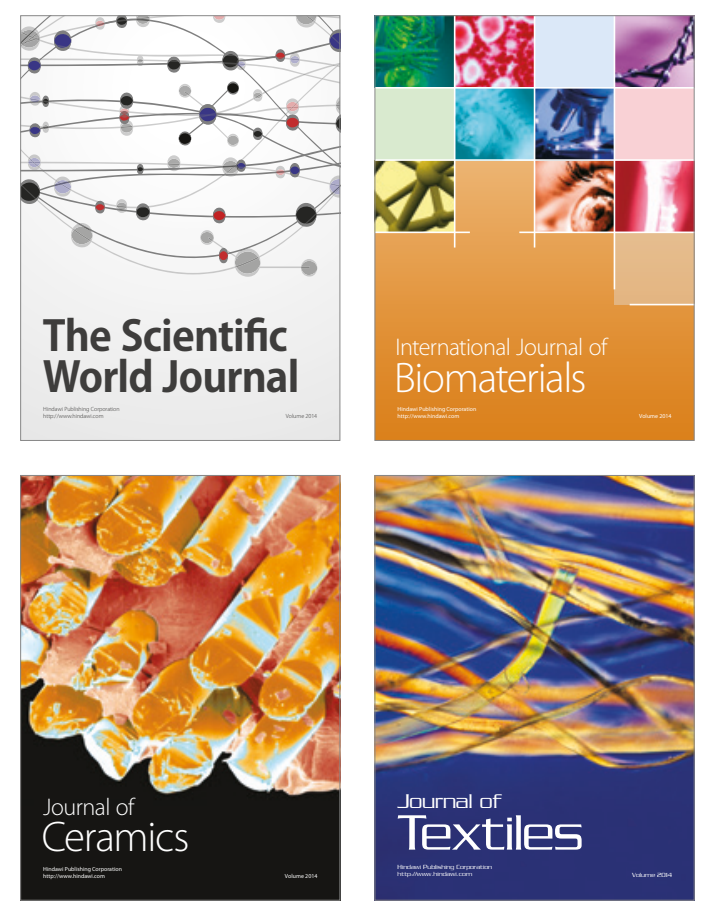